\title{
Effect of Cold Treatment as a Post-Harvest Treatment for Killing Immature Stages of the Peach Fruit Fly, Bactrocera zonata (Diptera: Tephritidae) and its Effect on Fruit Quality of Pomegranate Abd EL-Maaboud, A. S. ${ }^{\text {; }}$ Samia M. El-Oraby ${ }^{2}$ and Amal M. Hassan² \\ ${ }^{1}$ Plant Protection Research Institute, Agriculture Research Center \\ ${ }^{2}$ Horticulture Research Institute, Agriculture Research Center
}

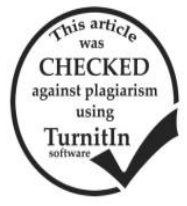

\section{ABSTRACT}

Pomegranate fruits were artificially infested with immature stages (eggs and larval instars) of peach fruit fly Bactrocera zonata and stored at $1.7^{\circ} \mathrm{C}$ for 14 days. Results showed that the effectiveness of cold treatment against B.zonata was demonstrated by $100 \%$ mortality in all immature stages. Also the results indicated that wonderful pomegranate fruits could be stored for 8 weeks (two weeks at $1.7^{\circ} \mathrm{C}$ plus six weeks at $10^{\circ} \mathrm{C}$ and $\mathrm{RH} 85-90 \%$ ) as storage or shipping temperature. Fruits transferred directly from quarantine treatment to room temperature $25 \pm 2^{\circ} \mathrm{C}$ and $\mathrm{RH} 45-50 \%$ had shelf life of two weeks without chilling injury symptoms plus two weeks at $1.7^{\circ} \mathrm{C}$. Concerning the data dealing with packing methods, carton box (5kilo) lined with perforated lifespan was the best in comparison with other methods.

Keywords: Cold treatment, Bactrocera zonata, pomegranate, Fruit quality.

\section{INTRODUCTION}

The peach fruit fly, Bactrocera zonata (Saunders) is considered as one of the most serious pests of fruits. As with many tropical tephritids, $B$. zonata has a wide host range including apple, guava, mango, peach, and orange (Steck, 2010). B. zonata was recorded for the first time in Egypt in 1998 and established rapidly in most Egyptian provinces causes great losses in all fruit crops (Mahmoud 2004, Khan et al. 2005). The percentages of apricot and citrus infested with $B$. zonata were higher than those infested with Ceratitis capitata and reached 20\% (Saafan et al., 2005a, and b). The establishment of the peach fruit fly in Egypt has been costing over $\$ 177$ million annually (Joomaye 1999).

Phytosanitary treatments are often required to export potential commodities that may carry invasive species to ecosystems where the species are not endemic but could become established (Heather and Hallman 2008). The Plant Protection and Quarantine Treatment Manual, Treatment Schedule T107(a) (USDA 1994), provides a cold treatment against Mediterranean fruit fly for fruits, including apple, apricot, grapefruit, kiwi, loquat, nectarine, orange, peach, persimmon, plum, pomegranate, and tangerine from many different countries. The cold treatment schedule consists of holding fruit at $0,0.6,1.1$, 1.7 , or $2.2^{\circ} \mathrm{C}$ for $10,11,12,14$, or $16 \mathrm{~d}$, respectively.

The number of days required for Phytosanitary cold treatments for $C$. capitata and Anastrepha ludens (Loew) at $1.7^{\circ} \mathrm{C}$ are 17 and 22, respectively (Animal and Plant Health Inspection Service [APHIS] 2013b).

The main problem associated with export and prolonged storage of pomegranate fruit are weight loss, shrinking, chilling injury and maintaining fruit quality during transport and storage El Oraby et. al (2009).

Lower temperature and high relative humidity has been reported to play a major role in maintaining the produce quality by reducing its rate of water loss Mahajan et. al (2008) Caleb et.al (2013b). Mulualem et.al (2014) found that packaging and cooling maintained the chemical quality of papay fruit towards the end of storage periods. LifeSpan modified atmosphere, modified humidity was the best treatment for maintining fruit quality of pomegranate during storage Mshraky et.al (2017). Miquel et.al (2004) found that variation of red color of pomegranate seeds during storage period at different storage temperatures may be due to the effect of storage temperature on the activity of the enzymes of the anthocyanin and biosynthetic pathway.

This research aims to study the effect of cold treatment at $1.7^{\circ} \mathrm{C}$ for 14 days on pomegranate fruits artificially infested with immature stages of $B$. zonata and on fruit quality before and after transferred to marketing and storage.

\section{MATERIALS AND METHODS}

\section{1-Rearing of the peach fruit fly $B$.zonata}

The peach fruit fly $B$. zonata used in this research was obtained from Horticultural Insects Research Department (PPRI). Larvae were reared on artificial diet. Adults flies kept in cages $(35 \times 35 \times 35 \mathrm{~cm})$ under laboratory conditions at $25 \pm 0.5^{\circ} \mathrm{C}, 65 \pm 5 \% \mathrm{RH}$ and a photoperiod $12: 12$ (L:D) and fed on a diet composed of sugar and enzymatic yeast hydrolysate at rate of 3:1 ,respectively. Eggs were collected from mature females (10-14days old) during one hour period before all treatments from a plastic orange, punctured from upper part and contained water inside to keep moisture for eggs.

\section{2-Artificial Infestation of Pomegranate:}

Freshly harvested pomegranate fruits variety 'Wonderful' from local orchards were cleaned, washed thoroughly with tap water, immersed in a disinfectant solution and allowed to air dry.

Fifty fresh eggs for each fruit were counted under stereoscope and arranged on black filter papers cards $(1 \mathrm{~cm} \times 1 \mathrm{~cm})$ wetted with distilled water.

Small cuts were conducted in pomegranate peels using sterilized cutter and cavities were made beneath using sharp spatulas.

Black filter paper cards loaded with eggs were transferred using sterilized forceps, inserted into fruit cavities, covered by pomegranate peel and secured with adhesive tape.

Forty pomegranate fruits were artificially infected by black filter paper cards loaded with eggs one week prior entering into cold chamber to obtain $3^{\text {rd }}$ larvae during treatment. After 2days a new 40 fruits were infected with eggs to obtain $2^{\text {nd }}$ larvae during treatment. Same procedure was repeated after another 2 days to obtain the $1^{\text {st }}$ larvae during treatment. The above three groups of infected fruits were incubated under laboratory condition at $25 \pm 1^{\circ} \mathrm{C}$ and $65 \pm 5 \% \mathrm{RH}$ to allow development all immature stages of $B$. 
zonata. The fourth and last group of fruits was infected by eggs on the day determined of entering fruits to cold chamber.

On the other hand, twenty pomegranate fruits (5 replicates each immature stages) as control were artificially infected by black filter paper cards loaded with eggs to obtain the all immature stages and incubated under laboratory condition at $25 \pm 1{ }^{\circ} \mathrm{C}$ and $65 \pm 5 \% \mathrm{RH}$ to allow development all immature stages of $B$. zonata to compare with cold treatment.

3-Cold Treatment Chamber:

The inner dimensions of cold chamber were 14.4 by 4.4 by $5 \mathrm{~m}$.

Plastic boxes loaded with infected fruits were distributed randomly in 8 sites inside of cold chamber representing different places and heights. Each site contained 20 fruits representing the four immature stages of $B$. zonata (5fruits loaded with eggs, 5 fruits contain $1^{\text {st }}, 5$ fruits contain $2^{\text {nd }}$ and 5 fruits contain $3^{\text {rd }}$ larval instars). At each site where infected fruits were placed thermographs which were fixed. The temperature inside cold chamber was observed by an internal sensor connected to an electronic panel fixed outside the chamber. When temperature reached $1.7^{\circ} \mathrm{C}$, the internal thermographs were set to start recording. Fruits were moved out cold chamber after 14 days of exposure and kept at $25^{\circ} \mathrm{C}$ for $24 \mathrm{~h}$ before being dissected and inspected under magnification to determine number of survived or killed larvae.

Effect of cold treatment of fruit quality:

Fruits were harvested when total soluble solid contents for juice attained level of $12-13 \%$ according to Arie et. al (1984). Fruits divided to three groups and packed as follows:

1- Fruits packed in carton boxes (5kilo) (control).

2- Fruits packed in carton boxes lined with perforated Lifespan (modified atmosphere packaging and modified humidity)(5 kilo)

3- Fruits packed in plastic boxes lined with Bargamin papers (5 kilo).

All these treatments were held at $1.7^{\circ} \mathrm{C}$ for 14 days as quarantine treatments, then three replicates from each treatment were transferred to room temperature $25 \pm 2{ }^{\circ} \mathrm{C}$ and $\mathrm{RH} 45-50 \%$ and other replicates were stored in a cold room $\left(10^{\circ} \mathrm{C}\right.$ and $\left.85-90 \% \mathrm{RH}\right)$ as shipping period.

Physical and chemical properties were determined (fruit weight loss - peel and seed color susceptibility to chilling injury, total soluble solids and titratable acidity percentage).

Chemical and physical properties were examined every 15 days for cold storage and every week for room temperature until the end of storage period.

Physical properties:

Fruit weight loss percentage:

Fruits were periodically weighed and the percentage of weight loss was calculated by the difference between the initial weight and that recorded at the date of sampling.

Peel and seeds color:

It was measured by using a hunter colorimeter type (dp 9000) for the estimation of a value (red color) according to Me gjuire (1992).
Chilling injury studies:

To check the susceptibility of pomegranate fruit to chilling injury, fruits were evaluated for external and internal symptoms (brown discoloration) during storage period at two storage temperatures.

Chemical properties:

Total soluble solids:

Percentage: was determined by Abbe, digital refrectometer. The titratable acidity as citric acid were determined according to A.O.A.C (1990)

Data obtained were statistically analyzed according to (Snedecor and Cochran, 1972) means for treatments were compared by L.S.D at 5\% level.

\section{RESULTS AND DISCUSSION}

Results obtained from Table (1) showed that cold treatment of pomegranate fruits at $1.7^{\circ} \mathrm{C}$ for 14 days as post-harvest treatment was effective as it caused $100 \%$ kill to all immature (eggs, $1^{\text {st }}$ larval instar, $2^{\text {nd }}$ larval instar and $3^{\text {rd }}$ larval instar) B. zonata.

Table 1. Total number of immature stages of $B$. zonata for control compared with cold treatment.

\begin{tabular}{lccccc}
\hline & \multicolumn{3}{c}{ Control treatment } & \multicolumn{2}{c}{ Cold treatment } \\
\cline { 2 - 6 } Stage & $\begin{array}{c}\text { No. } \\
\text { eggs } \\
\text { treated }\end{array}$ & $\begin{array}{c}\text { No. live } \\
\text { larvae } \\
\text { recovered }\end{array}$ & $\begin{array}{c}\text { Mortality } \\
\mathbf{( \% )}\end{array}$ & $\begin{array}{c}\text { No. live } \\
\text { larvae } \\
\text { recovered }\end{array}$ & $\begin{array}{c}\text { Mortality } \\
(\%)\end{array}$ \\
\hline Eggs & 250 & 234 & 6.4 & 0 & 100 \\
1st larval & 250 & 200 & 20 & 0 & 100 \\
2nd larval & 250 & 158 & 36.8 & 0 & 100 \\
3rd larval & 250 & 143 & 42.8 & 0 & 100 \\
\hline
\end{tabular}

These results agree with Hill et.al (1988) who stated that storage of orange for 16 days at $1.0 \pm 0.5^{\circ} \mathrm{C}$ resulted in $100 \%$ mortality of the most tolerant stage of $D$. tryoni and C.capitata.

Jessup et al. (1993) found that first instar of Bactrocera tryoni and the second instar of Ceratitis capitata were the most tolerant to $1 \pm 0.2^{\circ} \mathrm{C}$ for 14 days in two cultivars of lemons. While the third instar was the most cold-tolerant stage at 1.7 and $4^{\circ} \mathrm{C}$ when C. capitata was reared in guava, mango, and orange ("Navel" and Valencia) Hashem et al. (2004). Hallman et al. (2011) found that third instar of $B$. invadens was no more cold tolerant than third instar of Anastrepha ludens (Loew), Bactrocera dorsalis (Hendel), and Ceratitis capitata (Wiedemann) in vitro at $0.94 \pm 0.65{ }^{\circ} \mathrm{C}$. Hallman et al. (2013) represented that $B$. invadens is not more cold tolerant than C. capitata and B. zonata at $1.0 \pm 0.1^{\circ} \mathrm{C}$ but it cannot be concluded that $B$. zonata is not more cold tolerant than $C$. capitata in oranges.

Fruit weight loss percentage:

The data presented in tables (2.3.4) indicated that weight loss increased gradually and significantly after 2 weeks at $1.7^{\circ} \mathrm{C}$ and with advancing storage period at both storage temperatures $10^{\circ} \mathrm{C}$ and $25 \pm 2^{\circ} \mathrm{C}$. On the other hand the mean of fruit weight loss stored 3 weeks at room temperature $25 \pm 2^{\circ} \mathrm{C}$ had approximately 6 times at weight loss of fruit stored 6 weeks at $10^{\circ} \mathrm{C}$. Concerning the effect of packing method on fruit weight loss, treatment 2 tended to the lowest percentage in comparing with the other treatments at three storage temperatures.

The previous results were supported by Mahajan et.al (2008) and Caleb et.al (2013b) who reported that 
lower temperature and high relative humidity play a major role in reducing rate of water loss. Also, Santos et.al (2004) Malgarim et.al (2006) and El Etreby (2010) reported that polyethylene and polypropylene film minimized the weight loss.

Table 2. Effect of cold treatment at $1.7^{\circ} \mathrm{C}$ for two weeks on fruit quality of pomegranate fruit.

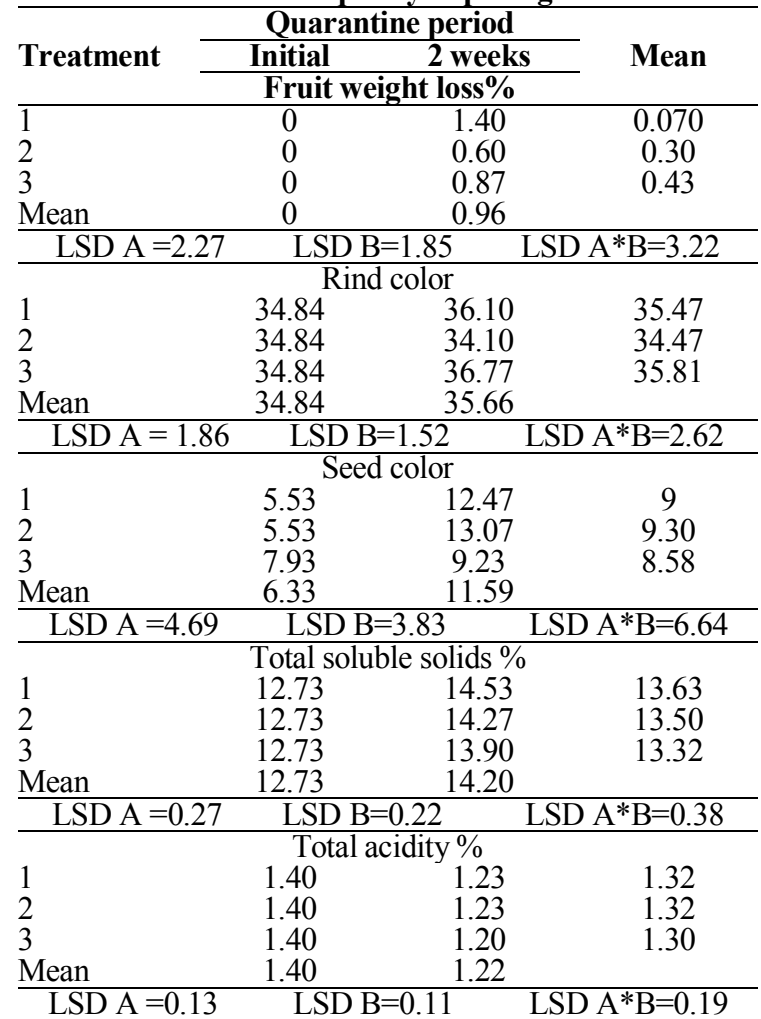

$A=$ Treatment $B=$ Storage period $A * B=$ Interaction

\section{Rind and seed color:}

The data in Tables (2.3.4) showed that no differences were found in rind color parameter (a) red color of fruits before and after quarantine period. The same results were found in fruits held at shipping $\left(10^{\circ} \mathrm{C}\right)$ or room temperature $\left(25 \pm 2^{\circ} \mathrm{C}\right)$. The results dealing with seed color revealed that parameter (a) increased significantly after quarantine period and during storage period at $10^{\circ} \mathrm{C}$ or at room temperature $25 \pm 2^{\circ} \mathrm{C}$ with some fluctuated at the last week of storage.

Data showed also that there was no obvious difference as means among treatments on rind and seed color during storage at the three different temperatures.

These results are in harmony with those found by Hamauzu and kumc (2005) who observed that phenolic and anthocyanin content increased at $1^{\circ} \mathrm{C}$ after storage 15 days in prunes fruit. Miquel et.al (2004) found that variation of red color during storage period at different temperatures may be due to the activity of the enzymes on the anthocyanin biosynthetic pathway.

T.S.S:

Data represented in Tables (2.3.4) showed that T.S.S of fruits stored 2 weeks at $1.7^{\circ} \mathrm{C}$ increased significantly in comparison with the beginning of storage.

After fruits were transferred to $10^{\circ} \mathrm{C}$ or $25 \pm 2^{\circ} \mathrm{C}$ the increase was slight till the end of storage period at $25 \pm 2{ }^{\circ} \mathrm{C}$ but T.S.S decreased at the last week of cold storage at $10^{\circ} \mathrm{C}$. The means among treatments showed that no difference on T.S.S during storage at three tested temperatures.

The pervious results were supported by Prasad and Mail (2000) Mshraky et.al (2017) who found that total soluble solids and total sugars increased with increased period of storage both at room as well as at low temperature.

Titratbale acidity:

With regard to the periodical changes in acidity it was evident from Tables (2.3.4) that acidity of fruits stored 2 weeks at $1.7^{\circ} \mathrm{C}$ had slight decrease in comparison with the beginning of storage. After fruits transferred to $10^{\circ} \mathrm{C}$ or $25 \pm 2^{\circ} \mathrm{C}$ the decrease was significant after two weeks from transferring. No obvious differences in means of acidity among packing treatments during storage at the three temperatures.

The decrease of acidity at the three temperatures may be due to the effect of temperature on respiration rate of fruits stored at $0^{\circ} \mathrm{C}$ or $10^{\circ} \mathrm{C}$ and ambient temperature $(\mathrm{El}$ Oraby et. al 2009). The decrease of acidity may be that organic acid are important as source of respiratory Zagory and kade (1989).

\section{Susceptibility to chilling injury and decay:}

No external or internal chilling injury symptoms or decay were observed on pomegranate fruits variety wonderful after quarantine period or on fruits stored at $10^{\circ} \mathrm{C}$ or at room temperature till the end of storage period. This result agree with data found by El Oraby et. al (2009) on pomegranate variety manfaloti.

Table 3. Effect of cold treatment on fruit quality after transfer to shipping or storage temperature 10 ${ }^{\circ} \mathrm{C}$ and 85- 90 RH.

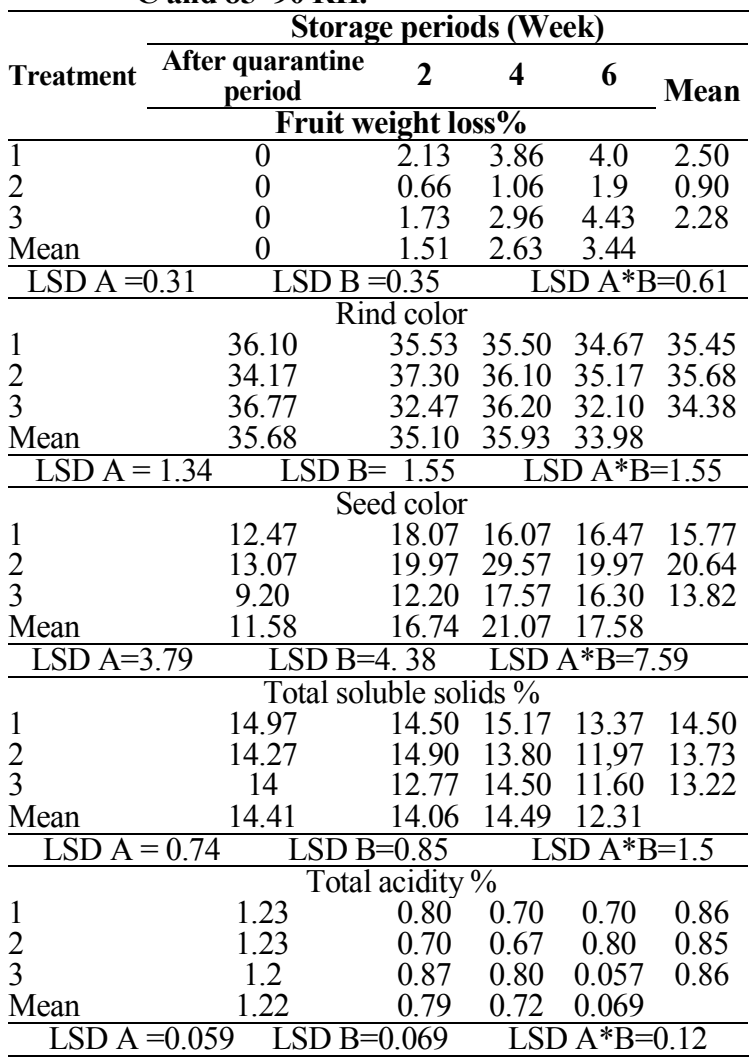


Table 4. Effect of cold treatment on fruit quality after transfer to room temperature $25 \pm 2^{\circ} \mathrm{C}$ and 45 50 RH.

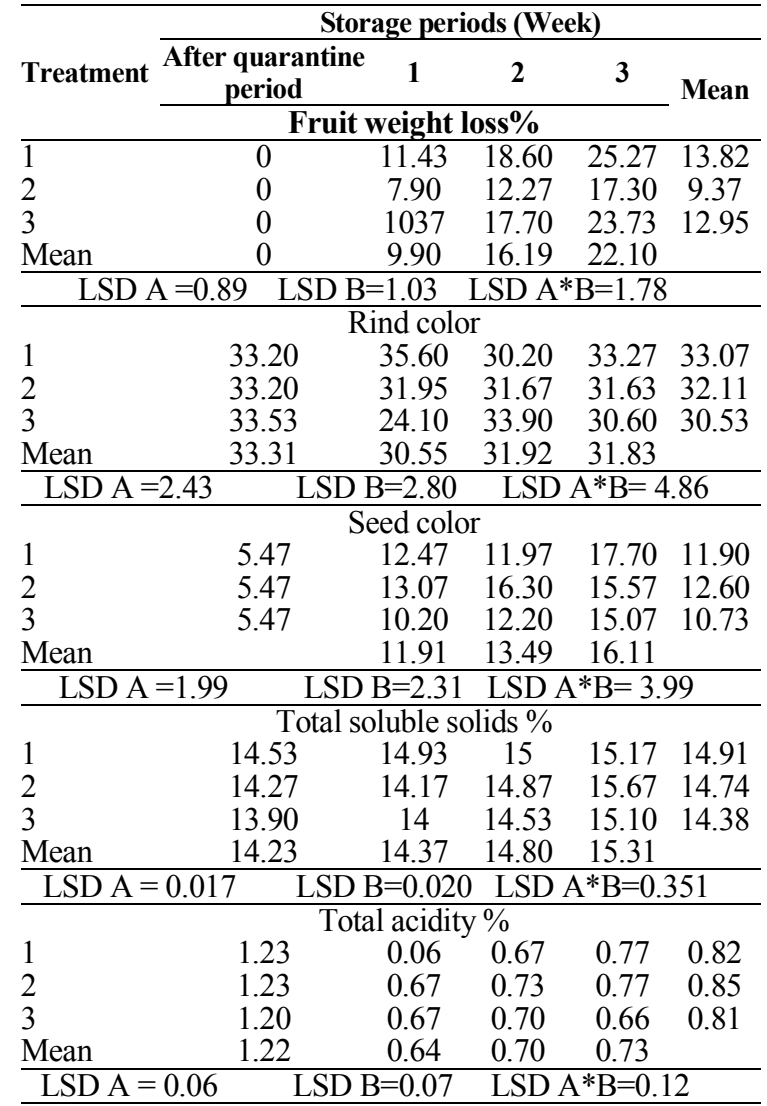

\section{CONCLUSION}

Cold treatment of pomegranate fruits for 14 days at $1.7^{\circ} \mathrm{C}$ resulted in $100 \%$ mortality of all immature stages (eggs, $1^{\text {st }}$ larval instar, $2^{\text {nd }}$ larval instar and $3^{\text {rd }}$ larval instar) $B$. zonata. So, this treatment was an effective a quarantine to kill both egg and larvae of $B$. zonata. According to fruit weight loss and quality the results indicated that pomegranate fruit variety wonderful could be stored for 8 weeks (two weeks at $1.7^{\circ} \mathrm{C}$ plus six weeks at $10^{\circ} \mathrm{C}$ and $85-90 \% \mathrm{RH}$ ) and 4 weeks (two weeks at $1.7^{\circ} \mathrm{C}$ ) plus two weeks at $25 \pm 2{ }^{\circ} \mathrm{C}$ and $\mathrm{RH} 45-50 \%$. These results are in agreement with those reported by Sercan et.al (2015) who found that pomegranate cultivars were monitored at refrigeration temperature for two months. Concerning the data dealing with packing methods, carton box (5kilo) lined with perforated lifespan was the best in comparison with other methods.

\section{ACKNOWLEDGMENT}

The authors wish to thank Prof. Dr. Talal S. ElAbbassi Head of the Horticultural Insect Research Department, Plant Protection Research Institute (PPRI) for advice and helpful, also we thanks Mr. Saeed Emam Ellaithy Manager of Three Fruits Company for helpful and allowed to produce this search.

\section{REFERENCES}

A.O.A.C (1990) Association of official of Agriculture chemists, official methods of analysis 11th Ed. Published by the A.O.A.C Washington D.C., U.S.A.

APHIS (2013b). Animal and Plant Health Inspection Service.. Treatment manual. U.S.Dept. Agric., Washington,D.C.(http://www.aphis.usda.gov/impor $\mathrm{t}$ export/plants/manuals/online_manuals.shtml).

Arie, R.B. N. Segal and Syivia Guefat 1984. Reich the maturation and ripening of the wonderful pomegranate. J.Amer.Soc.Hort. Sci. 109(6) 898902.

Caleb, O.J., Mahajan,P.V., Al Said, F.A, Opara,U.L (2013b) Transpiration rate and quality of pomegranate arils as affected by storage conditions. Cyta journal of Food doi 101080/19476337, 2012.721807.

El-Etreby,S.M (2010) Physiological studies on the postharvest handling and storage of plum fruits. Ph.D. Cairo University.

El-Oraby, Samia; A. Meshrake and A.M. Hassan (2009) Attempts to improve postharvest handling of pomegranate fruits to extend storage or shipping periods. Egypt .J. of Appl. Sci., 24(3B)

Hallman, G. J., S. W. Myers, A. J. Jessup, and A. Islam. (2011). Comparison of in vitro heat and cold tolerances of the new invasive species, Bactrocera invadens (Diptera: Tephritidae), with three known tephritids. J. Econ. Entomol.104: 21-25.

Hallman, G. J., S.W. Myers, M. F. El-Wakkad, M. D. Tadrous, and A. J. Jessup. (2013). Development of Phytosanitary cold treatments for oranges infested with Bactrocera invadens and B. zonata (Diptera: Tephritidae) by comparison with existing cold treatment schedules for Ceratitis capitata (Diptera: Tephritidae). J. Econ. Entomol. 106: 1608 -1612.

Hamauz, Y. and Kume, C. (2005) Change in fruit quality, phenolic compounds and antioxidant capacity on fresh prunes during storage. Acta Horticulture 682(1): 557-562.

Hashem, A. G., N. A. Soliman, and A. M. Soliman (2004). Effect of low temperatures on eggs and larvae of Mediterranean fruit fly and peach fruit fly inside fruits as a quarantine procedure. Ann. Agric. Sci. Moshtohor. 42:345-356.

Hashem, A. G., N. A. Soliman, and M.F.El-Wakkad (2002). Effect of cooling treatments on the development of the immature stages of Mediterranean fruit fly Ceratitis capitata (Wiedemann). (Diptera: Tephritidae). J. Agric. Mansoura Univ., 27(1): 603-612.

Heather, N. W., and G. J. Hallman (2008). Pest management and phytosanitary trade barriers. CABI, Wallingford, Cambridge, United Kingdom.

Hill, A. R., C. J. Rigney, and A. N. Sproul (1988). Cold storage of oranges as a disinfestation treatment against the fruit flies Dacus tryoni (Froggatt) and Ceratitis capitata (Wiedemann) (Diptera: Tephritidae). J. Econ. Entomol. 81:257-260. 
Jessup, A. J., C.P.F. De Lima, C.W. Hood, R. F. Sloggett, A. M. Harris, and M. Beckingham (1993). Quarantine disinfestation of lemons against Bactrocera tryoni and Ceratitis capitata (Diptera: Tephritidae) using cold storage. J. Econ. Entomol. 86: 798-802.

Joomaye, A., J. Knight and W. Routhier. (1999). Evaluation of the peach fruit fly problem in Egypt with recommendations for its control and eradication, including a limited cost-benefit analysis. A report on a mission to Egypt June 11 to June 24 1999. Project code: C3-INT/0/069 1301. 29pp.

Khan, M.A., M. Ashfaq, W. Akram and J.J. Lee, (2005). Management of fruit flies (Diptera: Tephritidae) of the most perishable fruits. Entomological Research, 35: 79-84.

Mahajan, P.V.; F.A.R. Oliviera and I. Macedo (2008)Effect of temperature and relative humidity on the transpiration rate of the whole mushrooms. Journal of Food Engineering, 84:281-288.

Mahmoud, Y.A (2004). Studies on the peach fruit fly, Bactrocera zonata (Saund.) with special reference to gamma ray. $\mathrm{PhD}$ Thesis Faculty of Science, Menoufia University, Egypt. Pp.: 163.

Malagarim, M.B; Cantillana, R.F.; Treptow, R.de and Souza, E.L.de (2006) Modified atmosphere during cold storage on postharvest quality of plums. Amarelinh Revista Brasileira de Agrocinencia, 12(1): 115-118.

Me.gjuire, R.Q. (1992) Reporting of objective color measurements. Hort. science 27(12)

Miguel, G.; F. Catarina; A. Dulce; N.Alcinda and Denise (2004) Anthocyanin concentration of Assaria pomegranate fruits during different cold storage conditions. J. Bioned Biotechnol (5):338-342.

Mshrky, A.M.; K. Nagy and O.M. Fekry (2017) Effect of modified atmosphere using some envelopes on fruit quality and storability on wonderful pomegranate cv.during storage Middle East. Journal of Applied Sciences vol.7 Jan-Mar page 92-101.

Mulualem, A.; Tilahum, S.W. and Kebede,W.(2014) Effect of packaging material and storage environment on postharvest quality of papaya fruit . Journal of food Science Technology vol 51(6): 1041-1055.
Prasad, R.N. and P.C. Mail (2000) Change in physic chemical characteristics of pomegranate squash during storage. Indian .J .of Hort. 27(1): 1820.

Saafan, M.H., Foda, S.M., and Abdel-Hafez, T.A. (2005a). Ecological studies of flies on different hosts at Fayoum Governorate. 3 - Ecological studies of Mediterranean fruit fly, Ceratitis capitata (Wied.) and Peach fruit fly, Bactrocera zonata (Saund.) in citrus orchards. Egyptian Journal of Agricultural Research, 83(3):11571170.

Saafan, M.H., Foda, S.M., and Abdel-Hafez, T.A. (2005b). Ecological studies of flies on different hosts at Fayoum Governorate. 3 - Ecological studies of Mediterranean fruit fly, Ceratitis capitata (Wied.) and Peach fruit fly, Bectrocera zonata (Saund.) in apricot orchards. Egyptian Journal of Agricultural Research, 83(4):16351648.

Santos, A.A.; Ribeiro, P.G; Ventura, C. and Bernalte, BM.J. (2004) The use of plastic film (Biorented polyprolyene) under cold condition to storage Rainha Claudia verd plums. No 52(1a) proceeding 5th International postharvest symposium, Verona,Italy 6-11June.

Sercan Karav, Ardico.A. and Azizeksi (2015) Effect of cold storage of various pomegranate cultivars fruit juices on health promoting compounds and their activities. Food and Nutrition Research vol. 3 (90):593-598.

Snedecor, G.W. and W.G. Cochran (1972) Statistical methods $6^{\text {th }}$ Ed. owa State Univ press, Ames, lowa.

Steck, G. J. (2010). A peach fruit fly, Bactrocera zonata (Saunders) (Tephritidae). Pest Alert No. DACSP-01751, Fla. Dep. Agric. Consumer Services, Dep. Plant Industry.

USDA. (1994) T107 (a): Cold treatment schedules for Ceratitis capitata (Mediterranean fruit fly), p.5.62.In Plant protection and quarantine treatment manual. USDA- APHIS, Hyattsville, MD.

Zagory and Kader (1989). Quality maintance in fresh fruits and vegetables by controlled atmosphere. American Chemical Society. Washington Dc. 14:174-187.

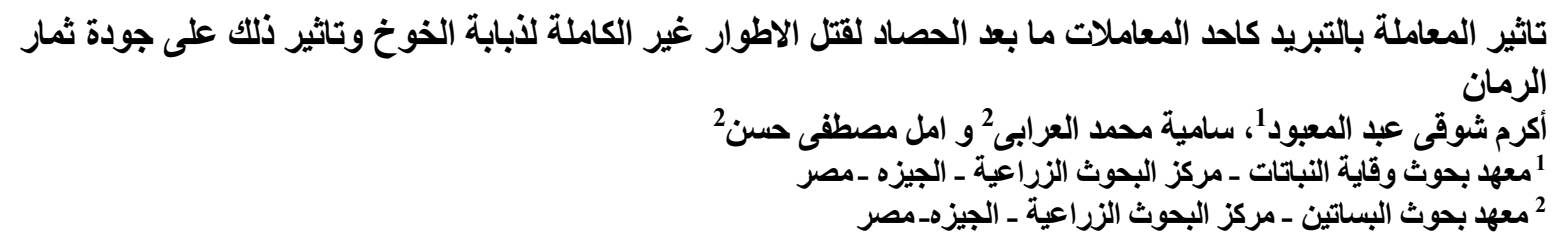

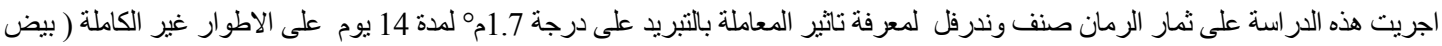

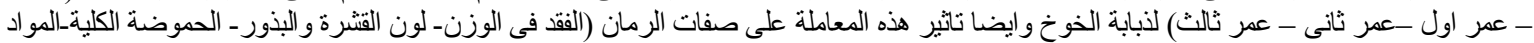

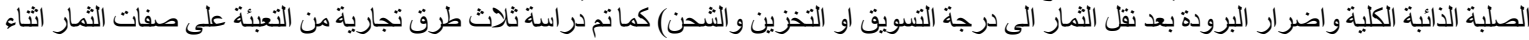

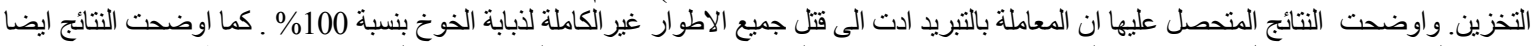

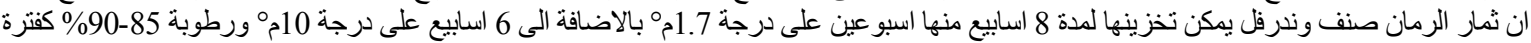

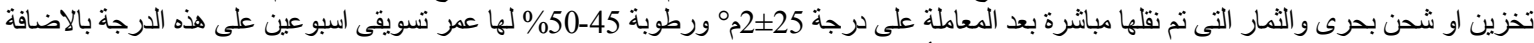

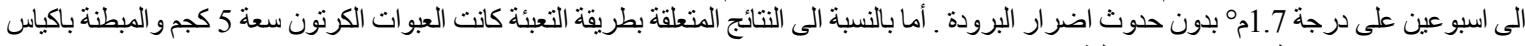
Life Span 